\title{
PREDIKSI HARGA SAHAM PT. ASTRA AGRO LESTARI Tbk. DENGAN JUMP DIFFUSION MODEL
}

\author{
Di Asih I Maruddani ${ }^{1}$, Trimono ${ }^{2}$ \\ ${ }^{12}$ Departemen Statistika Universitas Diponegoro \\ ${ }^{1}$ maruddani@undip.ac.id, ${ }^{2}$ trimonopujiarto@gmail.com
}

\begin{abstract}
Abstrak
Saham merupakan salah satu emiten yang paling banyak diperjualbelikan di pasar modal. Harga saham dan perubahannya merupakan dua indikator yang sering dijadikan bahan pertimbangan oleh para calon investor sebelum memutuskan untuk membeli saham suatu perusahaan. Harga saham hampir selalu mengalami perubahan, dan sulit diperkirakan bagaimana keadaannya pada periode yang akan datang. Terdapat berbagai metode yang dapat digunakan untuk memperikirakan harga saham pada periode yang akan datang. Diantaranya adalah pemodelan dengan Geometric Brownian Motion (GBM) dan pemodelan dengan Geometric Brownian Motion (GBM) dengan Jump. Metode GBM dapat memperediksi harga saham dengan baik apabila data return saham periode sebelumnya berdistribusi normal. Sedangkan jika pada data return saham periode sebelumnya memenuhi asumsi normalitas dan ditemukan adanya lompatan, maka digunakan metode Jump Diffusion. Prediksi harga saham AALI untuk periode 03/01/2017 sampai dengan 12/05/2017 dengan GBM menghasilkan akurasi peramalan yang baik, dengan nilai MAPE sebesar $11,26 \%$. Prediksi harga saham AALI untuk periode 03/01/2017 sampai dengan 12/05/2017 dengan metode Jump Diffuison menghasilkan akurasi peramalan yang sangat baik, dengan nilai MAPE sebesar 2,60\%. Berdasarkan nilai MAPE, model Jump Diffusion memberikan hasil yang lebih baik daripada model GBM.
\end{abstract}

Kata Kunci: geometric Brownian motion, jump diffusion model, saham, MAPE

\section{STOCK PRICE PREDICTION OF PT ASTRA ARGO LESTARI Tbk. WITH JUMP DIFFUSION MODEL}

\author{
Di Asih I Maruddani ${ }^{1}$, Trimono² \\ ${ }^{12}$ Department of Statistics Diponegoro University \\ ${ }^{1}$ maruddani@undip.ac.id, ${ }^{2}$ trimonopujiarto@gmail.com
}

\begin{abstract}
Stock is one of the most traded issuers in the capital market. Stock prices and changes are two indicators that are often taken into consideration by potential investors before deciding to buy shares of a company. The stock price almost always changes, and it is difficult to predict how it will be in the coming period. There are various methods that can be used to consider stock prices in the period to come. Among them are modeling with Geometric Brownian Motion (GBM) and modeling with Geometric Brownian Motion (GBM) with Jump. The GBM method can properly predict stock prices if the previous period share return data is normally distributed. Whereas if the stock return data of the previous period meet the assumption of normality and found a leap, then used Jump Diffusion method. AALI stock price prediction for the period 03/01/2017 to 12/05/2017 with GBM yielded good forecasting accuracy, with MAPE value of $11.26 \%$. AALI stock price prediction for the period 03/01/2017 to $12 / 05 / 2017$ with Jump Diffuison method produces excellent forecasting accuracy, with MAPE value of $2.60 \%$. Based on the MAPE value, the Jump Diffusion model gives better results than the GBM model.
\end{abstract}


Keywords: geometric Brownian motion, jump diffusion model, stock, MAPE

\section{PENDAHULUAN}

Pasar modal merupakan pasar berbagai instrumen keuangan jangka panjang yang bisa diperjualbelikan, baik dalam bentuk hutang maupun modal sendiri, baik yang diterbitkan oleh pemerintah, maupun perusahaan swasta. Di pasar modal, saham merupakan emiten yang paling banyak diperjualbelikan. Sebelum memutuskan menginvestasikan dananya untuk membeli saham sebuah perusahaan, investor akan melihat harga saham dan bagaimana perubahan harganya. Hampir setiap hari, harga saham selalu mengalami perubahan yang sulit untuk diprediksi. Secara umum, faktorfaktor yang mempengaruhi perubahan harga saham antara lain keadaan perusahaan, berita yang sedang berkembang, dan kondisi ekonomi suatu negara.

Karena pergerakan harga saham pada masa yang akan datang merupakan hal sulit untuk diprediksi, maka diperlukan model matematis yang dapat membantu untuk memprediksi harga saham pada masa yang akan datang. Penelitian ini secara khusus membahas metode Geometric Brownian Motion (GBM) dan metode Geometric Brownian Motion dengan jump atau Jump Diffusion untuk memprediksi harga saham pada masa yang akan datang. Metode GBM dan Jump
Diffusion dapat digunakan untuk memprediksi harga saham pada masa yang akan datang berdasarkan harga saham masa lalu. Metode GBM mengasumsikan bahwa return saham masa lalu berdistribusi normal. Sama halnya dengan metode GBM, metode Jump Diffusion juga mengasumsikan bahwa return saham masa lalu berdistribusi normal. Yang membedakan adalah, model Jump Diffusion dipakai apabila pada return saham masa lalu muncul lompatan.

Beberapa penelitian mengenai pemodelan harga saham telah banyak dilakukan. Abidin dan Jaffar (2014) meneliti tentang pemodelan harga saham dengan Geometric Brownian Motion pada beberapa perusahaan di Bursa Malaysia. Trimono, Maruddani, dan Ispriyanti (2017) meneliti mengenai valuasi harga saham PT Ciputra Tbk dengan Geometric Brownian Motion.

PT Astra Agro Lestari Tbk (AALI) merupakan perusahaan go public di Indonesia yang bergerak dalam bidang perkebunan. Saham AALI telah tercatat di Bursa Efek Indonesia (BEI) sejak tahun 1997. Salah satu prestasi yang dicatatkan oleh perusahaan ini adalah berhasil menduduki peringkat 5 besar dalam Daftar Saham Indeks LQ45 selama 3 periode terakhir. Penelitian ini membahas prediksi harga saham PT Astra Agro Lestari Tbk, 
untuk periode 3 Januari 2017 sampai dengan 12 Mei 2017.

\section{METODE}

\section{Return Saham}

Return saham adalah hasil yang diperoleh dari investasi dengan cara menghitung selisih harga saham periode berjalan dengan periode sebelumnya dengan mengabaikan dividen (Husnan, 2003). Analisis sekuritas umumnya menggunakan metode geometric return, dengan persamaan :

$$
R\left(t_{i}\right)=\ln \left(\frac{P\left(t_{i}\right)}{P\left(t_{i-1}\right)}\right)
$$

dengan $R\left(t_{i}\right)$ adalah nilai return saham periode $t_{i}, P\left(t_{i}\right)$ merupakan harga saham periode $t_{i}$, dan $P\left(t_{i-1}\right)$ menyatakan harga saham periode $t_{i-1}$.

\section{Volatilitas}

Menurut Maruddani dan Purbowati (2009), volatilitas merupakan besarnya harga fluktuasi dari sebuah asset. Jika terdapat sebanyak $n$ (banyaknya observasi) return, maka nilai ekspektasi return:

$$
\begin{aligned}
& \bar{R}=\frac{1}{n} \sum_{i=1}^{n} R\left(t_{i}\right) \\
& s^{2}=\frac{1}{n-1} \sum_{t=1}^{n}\left(R\left(t_{i}\right)-\bar{R}\right)^{2}
\end{aligned}
$$

dengan akar dari $s^{2}$ (variansi) merupakan estimasi volatilitas harga saham.

\section{Skweness}

Skewness adalah derajat ketidaksimetrisan suatu distribusi. Jika kurva frekuensi suatu distribusi memiliki ekor yang lebih memanjang ke kanan (dilihat dari meannya) maka dikatakan menceng kanan (positif) dan jika sebaliknya maka menceng kiri (negatif). Secara perhitungan, skewness adalah momen ketiga terhadap mean. Distribusi simetris (distribusi normal, distribusi t, distribusi Cauchy, dan lain-lain) memiliki skewness 0 (nol).

Perhitungan skewness adalah sebagai berikut (Surya dan Situngkir, 2006):

$$
\gamma_{1}=\frac{\frac{1}{N} \sum_{i=1}^{N}\left(x_{i}-\mu\right)^{3}}{\sigma^{3}}
$$

\section{Kurtosis}

Kurtosis adalah derajat keruncingan suatu distribusi (biasanya diukur relatif terhadap distribusi normal). Kurva yang lebih lebih runcing dari distribusi normal dinamakan leptokurtik, yang lebih datar platikurtik dan distribusi normal disebut mesokurtik. Kurtosis dihitung dari momen keempat terhadap mean. Distribusi normal atau mesokurtik memiliki kurtosis $=3$, distribusi yang leptokurtik biasanya kurtosisnya $>3$, dan platikurtik $<3$.

Pengukuran kurtosis dapat diukur dengan rumus (Surya dan Situngkir, 2006):

$$
\gamma_{2}=\frac{\frac{1}{N} \sum_{i=1}^{N}\left(x_{i}-\mu\right)^{4}}{\sigma^{4}}
$$


dengan $\mu_{\mu}$ adalah rata-rata populasi, yang nilainya dapat digunakan dengan rata-rata sampel $\bar{x}$ (untuk sampel besar).

Distribusi yang kelebihan kurtosis (leptokurtic) ditandai dengan nilai maksimum yang sempit namun sangat besar nilainya, dan ekor distribusi yang lebih gemuk daripada ekor disribusi Normal dan kelebihan kurtosis tersebut dapat dinyatakan sebagai

$\gamma_{2}^{\prime}=\gamma_{2}-3$

\section{Peak Over Treshold (POT)}

Peak Over Threshold merupakan salah satu metode dalam Extreme Value Theory. Pada distribusi simetris, khususnya distribusi normal, akan dipunyai

Expected Loss

$$
\int_{0}^{\mu} f(x) d x
$$

Unexpected Loss

$$
\int_{\mu}^{x_{\alpha}} f(x) d x
$$

Worse Case

$$
\int_{x_{\alpha}}^{\infty} f(x) d x
$$

Sehingga untuk distribusi simetris, dalam hal ini distribusi normal, jumlah data untuk kasus Worse Case adalah $W C=100(1-\alpha) \%$

\section{Persamaan Diferensial Stokastik}

Untuk model GBM, persamaan diferensial stokastik mengikuti persamaan :

$$
d X(t)=f(X(t)) d t+g(X(t)) d W(t)
$$

Kemudian untuk model Jump Diffusion, persamaan diferensial stokastik mengikuti persamaan :

$d X(t)=f(X(t)) d t+g(X(t)) d W(t)+X(t)$ $\mathrm{dJ}_{\mathrm{t}}$

dengan $f(X(t)) d t$ merupakan suku drift, $g(X(t)) d t$ merupakan suku difusi, $W(t)$ merupakan gerak Brown, dan $J_{t}$ merupakan proses Jump (Brigo et al, 2008).

\section{Model Harga Saham GBM}

Menurut Brigo et al 2008, model harga saham GBM memiliki persamaan awal :

$$
d P(t)=\mu P(t) d t+\sigma P(t) d W(t)
$$

Jika terdapat fungsi $G=G(P, t)$, berdasarkan teorema Ito fungsi tersebut dapat dinyatakan sebagai berikut :

$$
\begin{aligned}
d G= & \frac{\partial G}{\partial P(t)} \mu P(t) d t+\frac{\partial G}{\partial t} d t \\
& +\frac{1}{2} \frac{\partial^{2} P}{\partial S(t)^{2}} \sigma^{2} P(t)^{2} d t \\
& +\frac{\partial G}{\partial P(t)} \sigma P(t) d W(t)
\end{aligned}
$$

Misal fungsi $\mathrm{G}=\ln P(t)$, dengan $\frac{\partial G}{\partial P(t)}=\frac{1}{P(t)}, \frac{\partial^{2} G}{\partial P(t)^{2}}=-\frac{1}{P(t)^{2}}$, dan $\frac{\partial G}{\partial t}=0$, dan perubahan harga saham antar periode berselisih satu hari, maka model akhir untuk metode GBM adalah (Trimono, Maruddani, dan Ispriyanti, 2017):

$$
\hat{P}\left(t_{i}\right)=\hat{P}\left(t_{i-1}\right) \exp \left(\left(\hat{\mu}-\frac{\hat{\sigma}^{2}}{2}\right)\left(t_{i}-t_{i-1}\right)\right)
$$




$$
\exp \left(\hat{\sigma} \sqrt{t_{i}-t_{i-1}} Z_{i-1}\right)
$$

\section{Model Harga Saham Jump Diffusion}

Berdasarkan Matsuda (2004), persamaan diferensial stokastik dengan jump

$$
d S(t)=\mu S(t) d t+\sigma S(t) d W(t)+S(t) d J(t)
$$

$W(t)$ merupakan gerak Brown Standard. $J(t)$ adalah proses jump standard yang didefinisikan sebagai:

$$
\begin{aligned}
& J(t)=\sum_{j=1}^{N_{T}}\left(Y_{j}-1\right) \quad \text { dan } \\
& d J(t)=\left(Y_{N(t)}-1\right) d N(t)
\end{aligned}
$$

$N(t)$ adalah proses Poisson dengan intensitas $\lambda$ dengan $W(t), N(t)$, dan $Y(t)$ saling independen, dengan $W(t)$ merupakan Gerak Brown serta nilai $\mu$ dan $\sigma$ adalah parameter dari $X$ dan $t$. Menurut Cont dan Tankov (2004) Teorema Ito untuk jump diffusion model, jika terdapat fungsi $G=$ $G(X, t)$, maka fungsi $\mathrm{G}$ akan mengikuti persamaan berikut :

$$
\begin{aligned}
d G= & \left(\frac{\partial G}{\partial X(t)} \mu+\frac{\partial G}{\partial t}+\frac{1}{2} \frac{\partial^{2} G}{\partial X(t)^{2}} \sigma^{2}\right) d t \\
& +\frac{\partial G}{\partial X(t)} \sigma d W(t) \\
& +\left(G\left(X\left(t_{-}+\Delta X_{t}\right)-G\left(X\left(t_{-}\right)\right)\right)\right)
\end{aligned}
$$

Misalkan fungsi $\mathrm{G}=\ln \mathrm{S}(\mathrm{t})$, , dengan $\quad$ ketentuan $\quad \frac{\partial G}{\partial S(p)}=\frac{1}{S(p)}$, $\frac{\partial^{2} G}{\partial S(p)^{2}}=-\frac{1}{S(p)^{2}}, \quad$ dan $\quad \frac{\partial G}{\partial p}=0, \quad$ dan

perubahan harga saham periode berjalan dengan periode sebelumnya adalah satu hari dengan $p_{0}<p_{1}<p_{2} \ldots<p_{n}$, maka model akhir harga saham dengan Jump Diffusion Model adalah:

$$
\begin{aligned}
& d G=\left(\mu-\frac{\sigma^{2}}{2}\right) d p+\sigma d W(p)+\sum_{i=1}^{N_{t}} y_{i} \\
& \int_{p_{i-1}}^{p_{i}} d G=\int_{p_{I-1}}^{p_{i}}\left(\mu-\frac{\sigma^{2}}{2}\right) d p \\
& +\int_{p_{i-1}}^{p_{i}} \sigma d W(p)+\int_{p_{i-1}}^{p_{i}} \sum_{i=1}^{N_{t}} y_{i} d p \\
& \Leftrightarrow \ln \left(S\left(p_{i}\right)\right)-\ln \left(S\left(p_{i-1}\right)\right) \\
& =\left(\mu-\frac{\sigma^{2}}{2}\right)\left(p_{i}-p_{i-1}\right)+\sigma\left(W\left(p_{i}\right)-W\left(p_{i-1}\right)\right) \\
& +\sum_{i=1}^{N_{t}} Y_{i} \\
& \Leftrightarrow \ln \frac{S\left(p_{i}\right)}{S\left(p_{i-1}\right)} \\
& =\left(\mu-\frac{\sigma^{2}}{2}\right)\left(p_{i}-p_{i-1}\right)+\sigma\left(W\left(p_{i}\right)-W\left(p_{i-1}\right)\right) \\
& +\sum_{i=1}^{N_{t}} Y_{i} \\
& \Leftrightarrow \frac{S\left(p_{i}\right)}{S\left(p_{i-1}\right)} \\
& =\exp \left(\left(\mu-\frac{\sigma^{2}}{2}\right)\left(p_{i}-p_{i-1}\right)+\sigma\left(W\left(p_{i}\right)-W\left(p_{i-1}\right)\right)\right) \prod_{j=1}^{n_{t}} Y_{j} \\
& \Leftrightarrow \hat{S}\left(p_{i}\right) \\
& =\hat{S}\left(p_{i-1}\right) \exp \left(\left(\hat{\mu}-\frac{\hat{\sigma}^{2}}{2}\right)\left(p_{i}-p_{i-1}\right) \prod_{j=1}^{n_{t}} Y_{j}\right)
\end{aligned}
$$


$\exp \left(\left(\hat{\sigma} \sqrt{p_{i}-p_{i-1}} Z_{i-1}\right) \prod_{j=1}^{n_{t}} Y_{j}\right)$

Mean Absolute Percentage Error (MAPE)

Menurut Trimono, Maruddani, dan Ispriyanti (2017), MAPE merupakan metode yang dapat digunakan untuk mengevaluasi nilai peramalan dengan mempertimbangkan pengaruh besarnya nilai aktual. Perhitungan nilai MAPE adalah sebagai berikut:

$$
M A P E=\frac{\sum_{p=1}^{n}\left|\frac{Y_{p}-F_{p}}{Y_{p}}\right|}{n} \times 100 \%
$$

dengan $Y_{p}$ merupakan nilai aktual pada waktu ke $p . F_{p}$ merupakan nilai peramalan pada waktu ke $p . n$ merupakan banyaknya observasi.

Tabel 1. Skala Penilaian Akurasi MAPE

\begin{tabular}{cl}
\hline \multicolumn{1}{c}{$\begin{array}{c}\text { Nilai } \\
\text { MAPE }\end{array}$} & \multicolumn{1}{c}{ Akurasi Peramalan } \\
\hline$<10 \%$ & $\begin{array}{l}\text { Akurasi peramalan sangat } \\
\text { baik }\end{array}$ \\
$11 \%-20 \%$ & Akurasi peramalan baik \\
$21 \%-50 \%$ & $\begin{array}{l}\text { Akurasi peramalan masih } \\
\text { dalam batas wajar } \\
\text { Akurasi peramalan tidak } \\
>51 \%\end{array}$ \\
\hline
\end{tabular}

Sumber : Trimono, Maruddani, dan Ispriyanti (2017)

\section{Sumber Data dan Variabel Penelitian}

Penelitian ini menggunakan data harga penutupan saham AALI yang diperoleh dari website

http://finance.yahoo.com/quote/AALI. JK untuk periode 4/1/2016 sampai 12/5/2017.

\section{Tahapan Analisis Data}

Tahap analisis data untuk memodelkan dan memprediksi harga saham AALI dengan Jump Diffusion Model adalah sebagai berikut :

1. Menentukan data in sample dan dan out sample.

2. Menghitung nilai return saham data in sample dengan metode geometric return.

3. Uji normalitas data in sample return saham

4. Melakukan Peak Over Treshold data in sample return saham.

5. Melakukan estimasi parameter model harga saham GBM dan Jump Diffusion

6. Melakukan pemodelan dan prediksi harga saham dengan metode GBM dan Jump Diffusion.

7. Menghitung akurasi prediksi harga saham dengan metode MAPE.

\section{HASIL DAN PEMBAHASAN}

\section{Data In Sample dan Data Out Sample}

Data in sample terdiri 244 data harga penutupan saham, dan 243 data return saham yang dimulai dari periode 4/1/2016 sampai dengan 20/12/2016. Data out sample terdiri 84 data harga penutupan saham, yang dimulai dari periode 3/1/2017 sampai dengan 12/5/2017. Data return saham in sample selanjutnya akan 
digunakan untuk mencari nilai parameter model GBM dan model Jump Diffusion.

\section{Uji Normalitas Data In Sample Return}

\section{Saham}

Melalui uji normalitas KolmogorovSmirnov, menghasilkan nilai $\mathrm{D}_{\text {hitung }}$ sebesar 0,06037 dan nilai signifikansi sebesar 0,3386. Kesimpulannya, data in sample return saham berdistribusi normal, karena nilai signifikansi lebih besar dari nilai $\alpha$ $(0,05)$.

\section{Peak Over Treshold data in sample return saham}

Sebelum dilakukan Peak Over Treshold, perlu dilihat apakah terdapat lompatan pada data in sample return saham AALI. Adanya lompatan dapat dilihat dari nilai kurtosis. Jika nilai kurtosis lebih besar dari 3 (ekor gemuk/leptokurtosis) maka didalam data in sample return saham AALI dapat disimpulkan terdapat lompatan. Mengacu pada tabel 2, kurtosis data in sample return saham AALI memiliki nilai sebesar 5,42595 sehingga disimpulkan terdapat lompatan dalam data tersebut.

Tabel 2. Nilai Statistik Deskriptif

\begin{tabular}{ll}
\hline Statistik Deskriptif & Nilai \\
\hline Skewness & 0.12419 \\
Kurtosis & 5.42595 \\
\hline
\end{tabular}

Karena terdapat lompatan, maka selanjutnya dilakukan Peak Over Treshold terhadap data in sample return saham AALI. Peak Over Treshold dilakukan dengan cara menghitung nilai ambang batas bawah sebesar 10\%, dan nilai ambang batas atas sebesar $10 \%$.

Tabel 3. Nilai Ambang Batas Data Return Menggunakan Peak Over Threshold

\begin{tabular}{ll}
\hline Kuantil & Nilai \\
\hline Kuantil ambang batas bawah & $-0,02721$ \\
Kuantil ambang batas atas & 0,02647 \\
\hline
\end{tabular}

Dari tabel 3, kuantil ambang batas bawah merupakan batas bawah nilai data ekstrim atau lompatan yang ditentukan dari nilai return saham AALI dengan ambang batas $10 \%$ memiliki nilai $-0,02721$. Artinya nilai return yang lebih rendah dari $-0,02721$ merupakan lompatan yang terjadi pada data return AALI. Sebanyak 24 data bernilai negatif merupakan lompatan. Kemudian kuantil ambang batas atas merupakan batas atas nilai data ekstrim atau lompatan yang ditentukan dari nilai return saham AALI dengan ambang batas $10 \%$ memiliki nilai 0,02647 . Artinya nilai return yang lebih tinggi dari 0,02647 merupakan lompatan yang terjadi pada data return AALI. Sebanyak 24 data bernilai positif merupakan lompatan. 
Estimasi Nilai Parameter Model GBM

\section{dan Jump Diffuision}

a. Estimasi Nilai Parameter Model GBM.

Parameter dalam model GBM meliputi rata-rata return $(\alpha)$ dan volatilitas return $(\sigma)$. Berdasarkan tabel 4, diperoleh nilai estimasi ratarata return $(\alpha)$ sebesar 0,00027 dan nilai estimasi volatilitas return $(\sigma)$ sebesar 0,02308 .

Tabel 4. Estimasi nilai parameter model GBM

\begin{tabular}{ll}
\hline Parameter & Nilai \\
\hline Rata-rata return $(\alpha)$ & 0,00027 \\
volatilitas return $(\sigma)$ & 0,02308 \\
\hline
\end{tabular}

b. Estimasi Nilai Parameter Model Jump Diffuision

Parameter dalam model Jump Diffuision meliputi rata-rata return $(\alpha)$, volatilitas return $(\sigma)$, intensitas lompatan $(\lambda)$, rata-rata lompatan $(\mu)$, dan st.deviasi lompatan

Berdasarkan tabel 5, diperoleh nilai estimasi rata-rata return $(\alpha)$ sebesar 0,00027 dan nilai estimasi volatilitas return $(\sigma)$ sebesar 0,02308 , nilai estimasi intensitas lompatan $(\lambda)$ sebesar 0,00174, nilai estimasi ratarata lompatan $(\mu)$ sebesar 0,00426, dan nilai estimasi st.deviasi lompatan

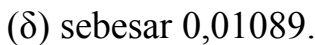

Tabel 5. Estimasi nilai parameter model Jump Diffuision

\begin{tabular}{ll}
\hline Parameter & Nilai \\
\hline rata rata return $(\alpha)$ & 0,00027 \\
volatilitas return $(\sigma)$ & 0,02308 \\
intensitas lompatan $(\lambda)$ & 0,00174 \\
rata-rata lompatan $(\mu)$ & 0,00426 \\
st.deviasi lompatan $(\delta)$ & 0,01089 \\
\hline
\end{tabular}

c. Model harga saham metode GBM

$\hat{S}\left(t_{i+1}\right)=\hat{S}\left(t_{i}\right) \exp \left(\left(\left(\hat{\alpha}-\frac{\hat{\sigma}^{2}}{2}\right)\left(t_{i+1}-t_{i}\right)\right)\right)$ $+\left(\hat{\sigma} \sqrt{t_{i+1}-t_{i}} Z_{i-1}\right)$

$\hat{S}\left(t_{i+1}\right)=\hat{S}\left(t_{i}\right) \exp \left(\left(0,00027-\frac{(0,02308)^{2}}{2}\right)\left(t_{i+1}-t_{i}\right)\right)$

$\exp \left(0,02308 \sqrt{t_{i+1}-t_{i}} Z_{i-1}\right)$

d. Model harga saham metode Jump Diffuision

$\hat{S}\left(t_{i+1}\right)=\hat{S}\left(t_{i}\right) \exp \left(\left(\hat{\alpha}-\frac{\hat{\sigma}^{2}}{2}-\hat{\lambda}\right)\left(t_{i+1}-t_{i}\right)\right)$

$\exp \left(\left(\hat{\sigma} \sqrt{t_{i+1}-t_{i}} Z_{i-1}\right)+N_{i}\right)$

$\hat{S}\left(t_{i+1}\right)=\hat{S}\left(t_{i}\right) \exp \left(\left(\left(0,00027-\frac{(0,02308)^{2}}{2}-0,00174\right)\left(t_{i+1}-t_{i}\right)\right)\right)$

$\exp \left(\left(0,02308 \sqrt{t_{i+1}-t_{i}} Z_{i-1}\right)+N_{i}\right)$

\section{Prediksi Harga Saham AALI}

Prediksi harga saham dimulai dari periode $03 / 01 / 2017$ sampai dengan periode 12/05/2017. Hasil prediksi harga saham dengan metode GBM dan Jump Diffuison dapat dilihat pada tabel 6 . 
Tabel 6. Harga Saham Aktual dan Prediksi AALI

\begin{tabular}{ccccc}
\hline t & Tanggal & Aktual & GBM & $\begin{array}{c}\text { Jump } \\
\text { Diffusion }\end{array}$ \\
\hline 1 & $03 / 01 / 2017$ & 16600 & 16693 & 16481 \\
2 & $04 / 01 / 2017$ & 16325 & 16688 & 16301 \\
3 & $05 / 01 / 2017$ & 16350 & 16186 & 15799 \\
4 & $06 / 01 / 2017$ & 16375 & 16460 & 15602 \\
5 & $09 / 01 / 2017$ & 16700 & 16377 & 15888 \\
6 & $10 / 01 / 2017$ & 16875 & 16210 & 16617 \\
7 & $11 / 01 / 2017$ & 17000 & 16072 & 16592 \\
8 & $12 / 01 / 2017$ & 17175 & 16057 & 16458 \\
9 & $13 / 01 / 2017$ & 16800 & 16595 & 16846 \\
10 & $16 / 01 / 2017$ & 16625 & 16992 & 17102 \\
11 & $17 / 01 / 2017$ & 16600 & 16429 & 17196 \\
12 & $18 / 01 / 2017$ & 16625 & 15572 & 16892 \\
13 & $19 / 01 / 2017$ & 16500 & 15319 & 16931 \\
14 & $20 / 01 / 2017$ & 16200 & 15376 & 17364 \\
15 & $23 / 01 / 2017$ & 16100 & 14976 & 17220 \\
16 & $24 / 01 / 2017$ & 16000 & 15584 & 16267 \\
17 & $25 / 01 / 2017$ & 15775 & 15396 & 15642 \\
18 & $26 / 01 / 2017$ & 15825 & 15496 & 15953 \\
19 & $27 / 01 / 2017$ & 15800 & 15643 & 15613 \\
20 & $30 / 01 / 2017$ & 15775 & 16128 & 15462 \\
21 & $01 / 02 / 2017$ & 16000 & 16570 & 15203 \\
22 & $02 / 02 / 2017$ & 16150 & 17418 & 15212 \\
23 & $03 / 02 / 2017$ & 16000 & 17704 & 15408 \\
24 & $06 / 02 / 2017$ & 16000 & 17553 & 14834 \\
25 & $07 / 02 / 2017$ & 15800 & 17614 & 15001 \\
26 & $08 / 02 / 2017$ & 15850 & 16828 & 14855 \\
27 & $09 / 02 / 2017$ & 15600 & 16748 & 15265 \\
28 & $10 / 02 / 2017$ & 15800 & 16972 & 15489 \\
29 & $13 / 02 / 2017$ & 15625 & 16749 & 15728 \\
30 & $14 / 02 / 2017$ & 15625 & 16239 & 15388 \\
31 & $16 / 02 / 2017$ & 15600 & 16191 & 14555 \\
32 & $17 / 02 / 2017$ & 15225 & 16227 & 14808 \\
33 & $20 / 02 / 2017$ & 15225 & 15915 & 14450 \\
34 & $21 / 02 / 2017$ & 15175 & 15380 & 14370 \\
35 & $22 / 02 / 2017$ & 14775 & 15436 & 14810 \\
36 & $23 / 02 / 2017$ & 14700 & 15668 & 15261 \\
37 & $24 / 02 / 2017$ & 14975 & 15766 & 15223 \\
38 & $27 / 02 / 2017$ & 15600 & 16381 & 15463 \\
39 & $28 / 02 / 2017$ & 14950 & 16177 & 15062 \\
40 & $01 / 03 / 2017$ & 15175 & 16232 & 15245 \\
& & & & \\
\hline
\end{tabular}

$\begin{array}{lllll}41 & 02 / 03 / 2017 & 15325 & 16981 & 14877\end{array}$ $42 \quad 03 / 03 / 2017 \quad 15275 \quad 17186 \quad 15302$

$43 \quad 06 / 03 / 2017 \quad 15300 \quad 17296 \quad 14999$

$44 \quad 07 / 03 / 2017 \quad 15275 \quad 18030 \quad 15177$

$\begin{array}{lllll}45 & 08 / 03 / 2017 & 15200 & 17768 & 14869\end{array}$

$\begin{array}{lllll}46 & 09 / 03 / 2017 & 15225 & 17366 & 14997\end{array}$

$\begin{array}{lllll}47 & 10 / 03 / 2017 & 15200 & 17457 & 14972\end{array}$

$48 \quad 13 / 03 / 2017 \quad 15025 \quad 17680 \quad 14941$

$49 \quad 14 / 03 / 2017 \quad 15125 \quad 17334 \quad 14981$

$\begin{array}{lllll}50 & 15 / 03 / 2017 & 15000 & 17407 & 15201\end{array}$

$\begin{array}{lllll}51 & 16 / 03 / 2017 & 15350 & 17681 & 15153\end{array}$

$\begin{array}{lllll}52 & 17 / 03 / 2017 & 15250 & 17317 & 14785\end{array}$

$\begin{array}{lllll}53 & 20 / 03 / 2017 & 15150 & 17563 & 14791\end{array}$

$\begin{array}{lllll}54 & 21 / 03 / 2017 & 15225 & 17662 & 15229\end{array}$

$\begin{array}{lllll}55 & 22 / 03 / 2017 & 15075 & 17665 & 15712\end{array}$

$\begin{array}{lllll}56 & 23 / 03 / 2017 & 15100 & 17529 & 15542\end{array}$

$\begin{array}{lllll}57 & 24 / 03 / 2017 & 14975 & 17244 & 15753\end{array}$

$\begin{array}{lllll}58 & 29 / 03 / 2017 & 15150 & 17389 & 15334\end{array}$

$\begin{array}{lllll}59 & 31 / 03 / 2017 & 14900 & 17141 & 14916\end{array}$

$\begin{array}{lllll}60 & 03 / 04 / 2017 & 15000 & 17360 & 15079\end{array}$

$\begin{array}{llllll}61 & 04 / 04 / 2017 & 15000 & 17820 & 14585\end{array}$

$\begin{array}{lllll}62 & 05 / 04 / 2017 & 14850 & 17570 & 14780\end{array}$

$\begin{array}{lllll}63 & 06 / 04 / 2017 & 14800 & 18030 & 15047\end{array}$

$\begin{array}{lllll}64 & 07 / 04 / 2017 & 14650 & 17486 & 15610\end{array}$

$\begin{array}{lllll}65 & 10 / 04 / 2017 & 14575 & 17656 & 15500\end{array}$

$\begin{array}{lllll}66 & 11 / 04 / 2017 & 14500 & 18031 & 15411\end{array}$

$\begin{array}{lllll}67 & 12 / 04 / 2017 & 14550 & 18188 & 15261\end{array}$

$\begin{array}{lllll}68 & 13 / 04 / 2017 & 14575 & 18057 & 14938\end{array}$

$69 \begin{array}{lllll}69 & 17 / 04 / 2017 & 14575 & 17501 & 14940\end{array}$

$\begin{array}{lllll}70 & 18 / 04 / 2017 & 14700 & 17097 & 14867\end{array}$

$\begin{array}{lllll}71 & 20 / 04 / 2017 & 14800 & 16830 & 14477\end{array}$

$\begin{array}{lllll}72 & 21 / 04 / 2017 & 14500 & 16316 & 15032\end{array}$

$\begin{array}{lllll}73 & 25 / 04 / 2017 & 14500 & 16294 & 15041\end{array}$

$\begin{array}{lllll}74 & 26 / 04 / 2017 & 14375 & 16149 & 14723\end{array}$

$\begin{array}{lllll}75 & 27 / 04 / 2017 & 14450 & 15987 & 14344\end{array}$

$\begin{array}{lllll}76 & 28 / 04 / 2017 & 14400 & 16247 & 14288\end{array}$

$\begin{array}{lllll}77 & 02 / 05 / 2017 & 14350 & 16862 & 14267\end{array}$

$\begin{array}{lllll}78 & 03 / 05 / 2017 & 14175 & 17112 & 14226\end{array}$

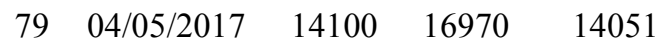

$80 \quad 05 / 05 / 2017 \quad 14150 \quad 17295 \quad 14412$

$81 \quad 08 / 05 / 2017 \quad 14525 \quad 17467 \quad 14873$

$\begin{array}{lllll}82 & 09 / 05 / 2017 & 14525 & 17631 & 14814\end{array}$

$83 \quad 10 / 05 / 2017 \quad 14200 \quad 17576 \quad 14714$ 
$\begin{array}{lllll}84 & 12 / 05 / 2017 & 14700 & 17998 & 15223\end{array}$

MAPE

Perhitungan nilai MAPE dilakukan dengan bantuan perangkat lunak R 3.3.2. Untuk model GBM, diperoleh nilai MAPE sebesar 11,26\% (akurasi peramalan masuk dalam kategori baik). Untuk model Jump Diffusion, diperoleh nilai MAPE sebesar 2,60\% (akurasi peramalan masuk dalam kategori sangat baik). Jika dilihat dari nilai MAPE, maka dapat disimpulkan bahwa untuk memprediksi harga saham AALI pada periode 03/01/2017 sampai dengan 12/05/2017 model Jump Diffusion memberikan hasil yang lebih baik daripada model GBM.

\section{KESIMPULAN}

Kesimpulan yang diperoleh berdasarkan analisis data harga saham AALI menggunakan model GBM dan Jump Diffusion adalah :

1. Model harga saham AALI dengan metode GBM :

$$
\begin{aligned}
\hat{S}\left(t_{i+1}\right)= & \hat{S}\left(t_{i}\right) \exp \left(\left(0,00027-\frac{(0,02308)^{2}}{2}\right)\left(t_{i+1}-t_{i}\right)\right) \\
& \exp \left(0,02308 \sqrt{t_{i+1}-t_{i}} Z_{i-1}\right)
\end{aligned}
$$

dengan nilai MAPE sebesar 11,26\%.
2. Metode Jump Diffusion lebih tepat digunakan untuk prediksi harga saham AALI karena menghasilkan error pemodelan yang lebih kecil dibandingkan metode GBM.

\section{DAFTAR PUSTAKA}

Abidin, S.N.Z. dan Jaffar, M.M. (2014). Forecasting Share Prices of Small Size Companies in Bursa Malaysia Using Geometric Brownian Motion. Applied Mathematics and Information Sciences. Vol 8 (1), 107-112.

Brigo et al. 2008. A Stochastic Processes Toolkit for Risk Management. Journal of Risk Management in Financial Institutions. Vol 1 (4), 513.

Cont, R. Dan Tankov, P. (2004). Financial Modeling with Jump Processes. Chapman \& Hall/CRC Financial Mathematics Series.

Husnan, S. 2003. Dasar-dasar Teori Portofolio dan Analisis Sekuritas. Edisi Ketiga. Yogyakarta : BPFE.

Maruddani, D.A.I. dan Purbowati, A. 2009. Pengukuran Value At Risk pada Aset Tunggal dan Portofolio dengan Simulasi Monte Carlo. Media Statistika. Vol 2 (2), 93-104

Matsuda, K. 2004. Introduction to Merton Jump Diffusion Model. The City University of New York Working Paper.

$$
\hat{S}\left(t_{i+1}\right)=\hat{S}\left(t_{i}\right) \exp \left(\left(\left(0,00027-\frac{(0,02308)^{2}}{2}-0,00174\right) \begin{array}{r}
\text { Rosso, G. }) \\
\left(t_{i+1} f o r\right) \\
\text { Threshold Method. Working Paper. }
\end{array}\right.\right.
$$

$\exp \left(\left(0,02308 \sqrt{t_{i+1}-t_{i}} Z_{i-1}\right)+N_{i}\right)$

dengan nilai MAPE sebesar 2,6\%.
Surya, Y. dan Situngkir, H. (2006). Value at Risk Yang Memperhatikan Sifat Statistika Distribusi Return. Munich 
Volume 3 No. 1., Mei 2017

Personal Repech Archives,

http://mpra.ub.uni-

muenchen.de/895.

Trimono, Maruddani D.A.I., Ispriyanti, D

(2017). Pemodelan Harga Saham

dengan Geometric Brownian Motion

dan Value At Risk PT. Ciputra

Development Tbk. Jurnal Gaussian.

Vol 6 (2). 